\title{
Effects and Problems of Continuous Infusion of Epoprostenol for Patients with Primary Pulmonary Hypertension
}

\author{
Tohru Takahashi, Masahito Sakuma, Jun Ikeda, Jun Nawata, Jun Demachi, \\ Osamu Kitamukai and Kunio ShiRATo
}

\begin{abstract}
Objective We examined the usefulness and the problems of epoprostenol (Epo) therapy in adult Japanese with primary pulmonary hypertension (PPH).

Subjects and Methods In eleven cases with PPH, both acute and chronic effects, and clinical effects of Epo were assessed.

Results In the acute challenge test $(\mathrm{n}=6)$, Epo reduced both systemic and pulmonary vascular resistance and increased the cardiac output, but did not change the ratio of pulmonary to systemic vascular resistance, while the systemic and pulmonary blood pressure also did not change. In the chronic study $(n=9)$, Epo decreased the pulmonary blood pressure without changes in systemic blood pressure, and increased the cardiac output. Both systemic and pulmonary vascular resistance decreased with a decrease in the ratio of the pulmonary to systemic vascular resistance. The level of brain natriuretic peptide and atrial natriuretic peptide, NYHA functional class and 6-minute walking distance were improved by Epo therapy. In spite of Epo therapy, two patients did not improve and died. Another patient improved in terms of symptoms but then died suddenly from massive lung bleeding. Two patients who improved physically could not be discharged because of psychiatric problems. One patient underwent lung transplantation. Five out-patients have been continuing Epo therapy.

Conclusion We demonstrated that the chronic effect of Epo treatment is sufficient even at the dose used in our hospital. However, it was shown that there was resistance to this therapy in some of the cases and that we should pay attention to the severe adverse effects of Epo.

(Internal Medicine 41: 784-788, 2002)
\end{abstract}

Key words: hemodynamics, cardiac output, vascular resistance, brain natriuretic peptide, 6-minute walking distance, out-patient

\section{Introduction}

Primary pulmonary hypertension (PPH) is well-known as one of the serious diseases (1-3). However, several new clinical therapies including continuous infusion of epoprostenol (Epo) (4-7) and lung transplantation (8) are recently being used in Japan. It has been reported that Epo therapy improves the prognosis compared with conventional therapy.

In this study, we described the method of Epo treatment and the problems of Epo therapy in Japan as well as the therapeutic results of adult cases of PPH who were treated with Epo continuous infusion in our hospital.

For editoriral comments, see $\mathrm{p} 757$.

\section{Subjects}

There were 15 possible cases for Epo treatment when this treatment was approved for insurance compensation in Japan in April 1999 (Fig. 1). The objects of this study were the patients with PPH who were diagnosed and started Epo treatment from April 1999 to December 2000. Eleven cases (two males and nine females; $32.2 \pm 12.2$ years old) were enrolled in this study. We confirmed the acute effects of Epo on the hemodynamics in 6 cases (one male and five females; $37.8 \pm 21.2$ years old) and the chronic effects in nine (two males and seven females; $32.4 \pm 12.8$ years old; five to 58 months, with a median of 24 months from the diagnosis of PPH by catheterization to the start of Epo).

In the Epo treatment cases $(n=11)$, two cases were administered calcium antagonists and three cases were administered anticoagulants simultaneously. In cases without Epo treatment $(n=4)$, two cases were administered calcium antagonists and the remaining two cases were administered beraprost sodium, an orally active Epo analogue, and three cases were administered anticoagulants. All cases were carefully diagnosed and we excluded intracardiac shunt diseases, diseases with post-

From Department of Cardiovascular Medicine, Tohoku University Graduate School of Medicine, Sendai

Received for publication September 19, 2001; Accepted for publication April 5, 2002

Reprint requests should be addressed to Dr. Kunio Shirato, Department of Cardiovascular Medicine, Tohoku University Graduate School of Medicine, 1-1 Seiryo-machi, Aoba-ku, Sendai, Miyagi 980-8574 


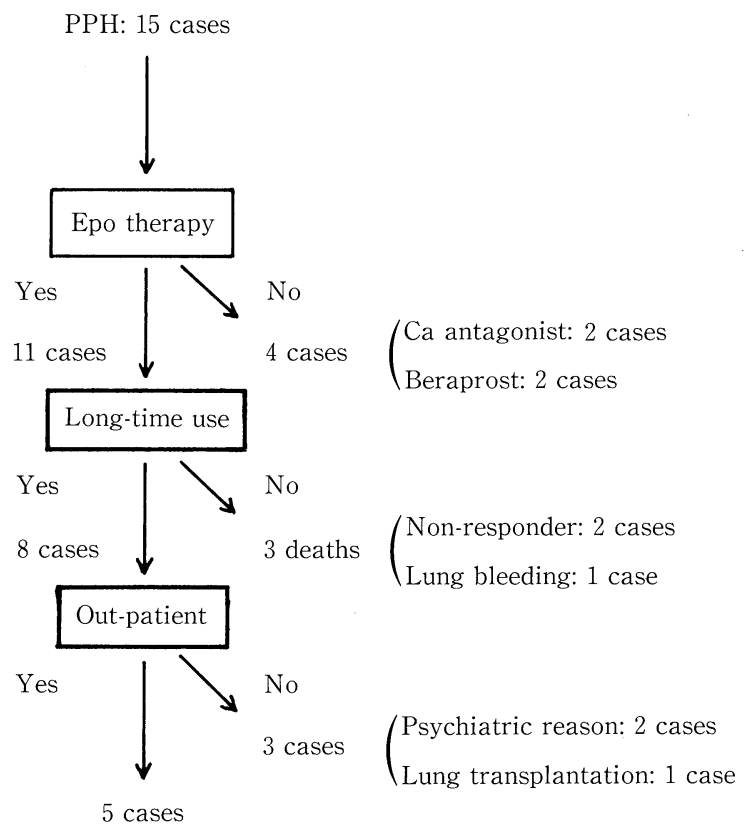

Figure 1. Medication in 15 patients with primary pulmonary hypertension. PPH: primary pulmonary hypertension, Epo: epoprostenol.

capillary pulmonary hypertension, secondary pre-capillary pulmonary hypertension from pulmonary diseases, pulmonary embolism, collagen diseases or portal hypertension.

\section{Methods}

After the routine examination, acute Epo challenge was carried out by catheter inspection. The baseline hemodynamic data were recorded, and then Epo infusion was started from the initial dose $(2 \mathrm{ng} / \mathrm{kg} / \mathrm{min})$ for each case and the dose of Epo was increased by $2 \mathrm{ng} / \mathrm{kg} / \mathrm{min}$ every 10 minutes until $10 \mathrm{ng} / \mathrm{kg} / \mathrm{min}$. The hemodynamics were recorded every 10 minutes after increasing the dose of Epo. When these patients complained of either nausea or headache, or revealed hypotension or tachycardia (a heart rate increases of $40 \mathrm{bpm}$ or over $120 \mathrm{bpm}$ ), the recording was carried out. We recorded the pulmonary capillary wedge pressure, pulmonary artery pressure, right atrial pressure, and cardiac output using a Swan-Ganz catheter. We recorded the aortic pressure using a fluid-filled catheter by a radial approach. And we also measured the mixed venous blood oxygen partial pressure.

The indications for Epo continuous infusion were the following: (1) patients with NYHA III or IV whose pulmonary vascular resistance did not decrease by $30 \%$ in the acute challenge of Epo or nitric oxide, (2) patients whose right side heart failure could not be controlled by beraprost sodium administration and (3) patients who were not controlled by conventional therapy including oxygen inhalation and calcium antagonist administration even if the results of the acute challenge
Table 1. Acute Effect of Epo on Hemodynamics $(n=6)$

\begin{tabular}{|c|c|c|c|c|}
\hline & & Baseline & Epo & $P$ value \\
\hline mPCWP & $(\mathrm{mmHg})$ & $6.7 \pm 2.7$ & $8.7 \pm 2.7$ & 0.11 \\
\hline mPAP & $(\mathrm{mmHg})$ & $62.5 \pm 15.5$ & $63.8 \pm 14.5$ & 0.66 \\
\hline mRAP & $(\mathrm{mmHg})$ & $8.2 \pm 2.8$ & $8.3 \pm 1.8$ & 0.89 \\
\hline mAoP & $(\mathrm{mmHg})$ & $78.7 \pm 9.2$ & $75.3 \pm 9.2$ & 0.17 \\
\hline $\mathrm{CO}$ & $(l / \min )$ & $2.57 \pm 0.58$ & $3.70 \pm 0.90$ & 0.012 \\
\hline PVR & (dyne $\cdot \mathrm{sec} / \mathrm{cm}^{5}$ ) & $1,769 \pm 451$ & $1,266 \pm 401$ & 0.0006 \\
\hline SVR & $\left(\right.$ dyne $\cdot \mathrm{sec} / \mathrm{cm}^{5}$ ) & $2,321 \pm 725$ & $1,578 \pm 639$ & 0.0059 \\
\hline PVR/SVR & & $0.80 \pm 0.22$ & $0.84 \pm 0.24$ & 0.49 \\
\hline $\mathrm{Ca} \mathrm{O}_{2}$ & (Vol.\%) & $18.2 \pm 4.2$ & $17.3 \pm 2.6$ & 0.40 \\
\hline $\mathrm{Cv} \mathrm{O}$ & (Vol.\%) & $10.6 \pm 3.8$ & $11.5 \pm 3.4$ & 0.27 \\
\hline $\mathrm{AV} \mathrm{O}_{2}$ diff. & (Vol.\%) & $7.6 \pm 1.2$ & $5.8 \pm 0.9$ & 0.034 \\
\hline
\end{tabular}

mPCWP: mean pulmonary artery wedge pressure, mPAP: mean pulmonary artery pressure, mRAP: mean right atrial pressure, mAoP: mean aortic pressure, $\mathrm{CO}$ : cardiac output, PVR: pulmonary vascular resistance, SVR: systemic vascular resistance, $\mathrm{Ca} \mathrm{O}_{2}$ : arterial oxygen content, $\mathrm{Cv}_{2}$ : mixed venous oxygen content, $\mathrm{AV} \mathrm{O}_{2}$ diff.: arteriovenous difference in oxygen content. See Figure 1 for other abbreviations.

showed it to be effective.

For chronic Epo infusion, a Hickman catheter (Bard Access Systems, Inc., Salt Lake City, Utah, USA) was inserted into the superior vena cava through the subclavian vein by the skin tunnel approach. Epo infusion was carried out using a portable continuous infusion pump (CADD Legacy Plus, Deltec Co., St. Paul, MN, USA).

All data were described as mean \pm standard deviation and paired t-test and Wilcoxon matched-pairs signed-rank test were used for statistical comparisons.

\section{Results}

\section{Acute effect of Epo (Table 1)}

The maximum doses of Epo in the 6 cases averaged 8.3 \pm 1.5 $\mathrm{ng} / \mathrm{kg} / \mathrm{min}(6-10 \mathrm{ng} / \mathrm{kg} / \mathrm{min})$ in the acute challenge. A decline in the pulmonary vascular resistance of less than $30 \%$ (nonresponder) was found in 4 cases. The systemic and pulmonary blood pressure did not change significantly. Although the pulmonary vascular resistance was reduced with the increase in cardiac output, the ratio of the pulmonary to systemic vascular resistance did not change significantly.

Neither the arterial nor mixed venous oxygen content changed significantly in the acute challenge. However, the arterio-venous difference in oxygen content was decreased.

\section{Chronic effects of Epo (Table 2)}

In the pressure data, the pulmonary arterial pressure decreased and right atrial pressure, systemic blood pressure and pulmonary arterial capillary wedge pressure were unchanged. Cardiac output increased and both pulmonary and systemic vascular resistance decreased. The ratio of the pulmonary to 
Table 2. Chronic Effect of Epo on Hemodynamics (n=9)

\begin{tabular}{llccc}
\hline & & Baseline & Follow-up & P value \\
\hline mPCWP & $(\mathrm{mmHg})$ & $10.6 \pm 5.2$ & $9.8 \pm 2.3$ & 0.44 \\
mPAP & $(\mathrm{mmHg})$ & $71.9 \pm 19.2$ & $58.9 \pm 18.1$ & 0.01 \\
mRAP & $(\mathrm{mmHg})$ & $12.0 \pm 6.2$ & $8.7 \pm 3.0$ & 0.12 \\
$\mathrm{mAoP}$ & $(\mathrm{mmHg})$ & $85.9 \pm 12.9$ & $85.9 \pm 15.5$ & 0.38 \\
$\mathrm{CO}$ & $(l / \mathrm{min})$ & $2.85 \pm 0.71$ & $4.15 \pm 0.81$ & 0.0013 \\
$\mathrm{PVR}$ & $\left(\right.$ dyne $\left.\cdot \mathrm{sec} / \mathrm{cm}^{5}\right)$ & $1,738 \pm 421$ & $991 \pm 495$ & 0.0002 \\
$\mathrm{SVR}$ & $($ dyne·sec/cm & $2,157 \pm 552$ & $1,529 \pm 435$ & 0.014 \\
$\mathrm{PVR} / \mathrm{SVR}$ & & $0.85 \pm 0.24$ & $0.64 \pm 0.19$ & 0.037 \\
$\mathrm{Ca} \mathrm{O}$ & & $16.7 \pm 2.2$ & $17.0 \pm 1.8$ & 0.08 \\
$\mathrm{CvO}_{2}$ & $($ Vol.\%) & $10.3 \pm 2.5$ & $12.3 \pm 1.4$ & 0.032 \\
$\mathrm{AV} \mathrm{O}_{2}$ diff. & $($ Vol.\%) & $6.5 \pm 2.3$ & $4.8 \pm 1.8$ & 0.0006 \\
\hline
\end{tabular}

See Table 1 for abbreviations.

systemic vascular resistance decreased.

The arterial content of oxygen did not change significantly but the mixed venous content of oxygen increased. And the arterio-venous difference in oxygen content decreased.

In the chronic period of Epo infusion, atrial natriuretic peptide (ANP) and brain natriuretic peptide (BNP) decreased significantly ( $183 \pm 92$ to $72 \pm 47 \mathrm{pg} / \mathrm{ml}, \mathrm{p}=0.018$ and $397 \pm 214$ to $112 \pm 109 \mathrm{pg} / \mathrm{ml}, \mathrm{p}=0.001$, respectively), and the 6-minute walking distance increased ( $221 \pm 104$ to $356 \pm 95 \mathrm{~m}, \mathrm{p}=0.0074)$.

\section{Clinical course in PPH patients using continuous Epo infu- sion (Fig. 2)}

The increase in the dose of Epo after hospitalization is shown in Fig. 2. The initial dose was $0.5-8 \mathrm{ng} / \mathrm{kg} / \mathrm{min}$ (average 2.2 $\mathrm{ng} / \mathrm{kg} / \mathrm{min}$ ), and the average doses after 6 months and 1year were $14.5 \mathrm{ng} / \mathrm{kg} / \mathrm{min}$ ( 6 cases) and $20.8 \mathrm{ng} / \mathrm{kg} / \mathrm{min}$ (4 cases), respectively.

Three patients died during the study period ( 5 days, 2 weeks, and 8 months after Epo therapy was started). Two of these patients were non-responders to the acute challenge of Epo. They died of right ventricular failure despite of Epo therapy. And another patient, whose clinical course had been improving, died suddenly of massive lung bleeding. Two patients who improved clinically could not be discharged because of psychiatric problems. One patient underwent lung transplantation in our hospital. Five out-patients have continued Epo therapy.

\section{Clinical effect}

Most of the cases enrolled in this study improved in clinical status as evaluated by the NYHA functional class. No case revealed a deterioration (see Fig. 3).

The frequency of adverse effects of Epo were as follows: warmth $(100 \%)$, jaw pain $(100 \%)$, joint and/or muscle pain $(100 \%)$, abdominal discomfort (72\%), diarrhea (36\%), and hemorrhagic tendency (18\%).

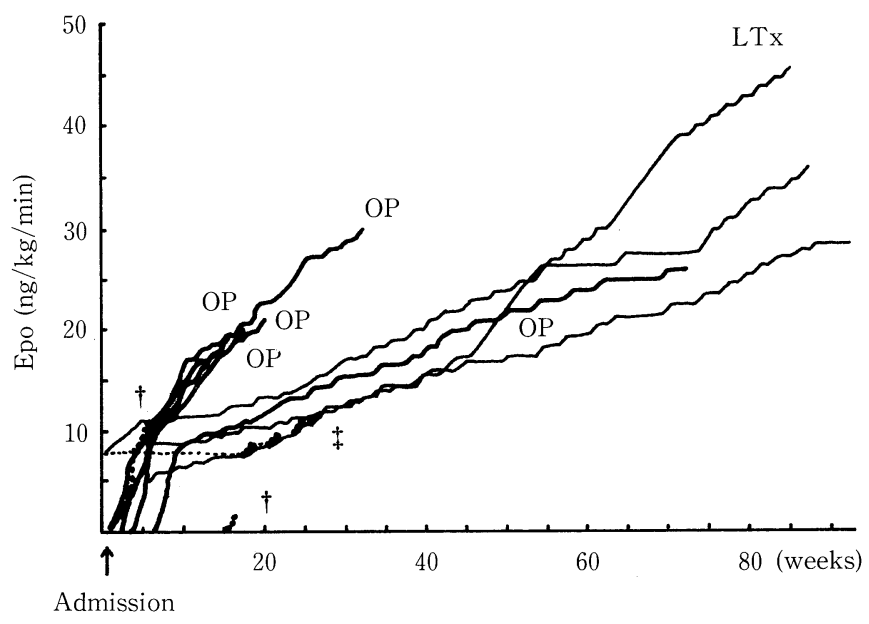

Figure 2. Epoprostenol increase in primary pulmonary hypertension patients. OP: out-patient, $\dagger$ : death from right ventricular failure, \$: death from sudden lung bleeding, LTx: lung transplantation.



Figure 3. Effect of epoprostenol on NYHA functional class $(n=11)$. Solid lines show alive patients and broken lines show dead patients. $\uparrow$ : death from right ventricular failure, $\neq$ : death from sudden lung bleeding.

\section{Discussion}

PPH is a disease with a poor prognosis and there had been no effective medical treatment except high-dose calcium antagonists which are effective in only one-third of the patients(1- 
3). The clinical use of Epo was started in 1999 in Japan. However, there are no guidelines for the determination of the initial dosage and substantial gradual increase in the dosage. In the early days of Epo treatment in Europe, the dose that induced a clinical improvement was maintained and it was increased only when the symptoms worsened (9). On the other hand, aggressively increasing the dose of Epo has became a recent trend because of improvement in the prognosis. Barst et al (10) have reported increasing the dose up to $100 \mathrm{ng} / \mathrm{kg} / \mathrm{min}$ within a year. They recommended actively increasing the dose and using the largest dose possible. They stopped increasing the dose only in high output $(4,10)$. On the other hand, in our results, the dose of Epo reached $20 \mathrm{ng} / \mathrm{kg} / \mathrm{min}$ by 1 year in the severe heart failure cases and $20 \mathrm{ng} / \mathrm{kg} / \mathrm{min}$ by $2-5$ months in the relatively stable cases. We stopped increasing the dose when there was an improvement in symptoms and decline in the pulmonary vascular resistance. Our regimen was mainly restricted by the cost of Epo and due to the unique system of medical insurance in Japan. The Epo dose used in this study was lower than that commonly used in the USA, although it was larger than the dose used in the early period in Europe. However, we showed that a sufficient clinical effect could be obtained even at the dose that we used in terms of the chronic hemodynamic effect and NYHA functional class.

\section{Selection of the subjects for Epo therapy}

Although the indications for Epo treatment have not been established, it is generally accepted for cases over NYHA class III that do not respond to acute challenge of pulmonary vasodilators in a catheter study, because it has been demonstrated that, in most of the patients with PPH, Epo treatment yields a long-term improvement even with non-responders in the acute challenge test, and that other vasodilators do not. Patients that react to pulmonary vasodilators are considered suitable candidates for high-dose calcium antagonists and beraprost sodium (7).

We adopted continuous Epo infusion for 4 non-responders and a responder whose cardiac output was extremely low. We also adopted continuous Epo infusion for the cases with NYHA class III or IV, even if they did not undergo the catheterization, when the patients accepted this treatment. Moreover, continuous Epo infusion may be allowed for the patients with $\mathrm{PPH}$ and severe right heart failure that can not be improved by conventional therapy and the concomitant use of cardiotonic agents (11).

\section{Comparison between the acute and chronic effects of Epo}

The acute effect of Epo on patients with PPH was a reduction of both the systemic and pulmonary vascular resistance, and increased cardiac output while the systemic and pulmonary blood pressure did not change. The acute effects of Epo had no selectivity for pulmonary arteries because the ratio of the pulmonary to systemic vascular resistance did not change. Among the 6 cases with PPH who underwent acute challenge by catheterization, 2 cases whose pulmonary vascular resistance decreased more than $30 \%$ were diagnosed as responders, and four cases were non-responders.

In the chronic period of Epo infusion, the pulmonary blood pressure decreased without changes in the systemic blood pressure and the cardiac output increased. Both systemic and pulmonary vascular resistance decreased, while the ratio of the pulmonary to systemic vascular resistance decreased so that the effects in the chronic period revealed high selectivity to the pulmonary arteries. The mechanism behind the difference between the acute and chronic effects of Epo treatment has not been elucidated. Some investigators reported that the chronic effects of Epo are related to the inhibition of the release of platelet-derived growth factor from the platelets, and the inhibition of hypertrophy or fibrosis in the middle layer of the pulmonary arterial wall (12).

In the clinical parameters, as BNP and ANP decreased, and the 6-minute walking distance increased in parallel with the decrease in pulmonary vascular resistance as also shown in the previous reports (13-15). Nagaya et al suggested that these are useful in the evaluation of the severity of PPH and the effectiveness of Epo (13). Continuous Epo infusion improves the clinical symptoms and the exercise tolerance, so that the timing of lung transplantation can be postponed (4-6). Epo had no vascular selectivity in the acute phase (16) but there was selective vasodilation to pulmonary artery in the chronic phase (4-6).

\section{Problems of Epo treatment}

Previous reports showed that some cases do not respond to long-term use of Epo therapy (17). In the present study, we encountered two non-responders of long-term use who deteriorated to right heart failure very rapidly (7). It is known that a deterioration of the symptoms can be caused by Epo in pulmonary veno-occlusive disease (17), but it is not clear what kind of patient is resistant to this treatment (17).

There are some problems concerning continuous Epo infusion at home, including infection, thrombosis $(4,10)$ and psychiatric disorder. Even after sufficient explanation of this treatment and obtaining informed consent, there are some patients who request to stop the therapy or stop infusion by themselves because of psychiatric problems, especially young patients. The management of these cases was also very difficult without Epo and we could not discontinue Epo infusion. In such cases, psychotherapeutic consultation is needed as well as long-term admission for continuing this treatment.

Concerning the cost, Epo is very expensive. Some of our patients incurred costs of over 200,000 yen/day for Epo. Such a large economic burden is an issue that needs to be addressed in view of the increasing pressure to reduce medical costs.

\section{Conclusion}

We demonstrated that the chronic effect of Epo treatment is sufficient even at the dose used in our hospital. However, it was shown that there was resistance to this therapy in some of the cases and that we should pay attention to the severe adverse effects of Epo. 


\section{TAKAHASHI et al}

\section{References}

1) D'Alonzo GE, Barst RJ, Ayres SM, et al. Survival in patients with primary pulmonary hypertension. Ann Intern Med 115: 343-349, 1991.

2) Rich S, Dantzker DR, Ayres SM, et al. Primary pulmonary hypertension. Ann Intern Med 107: 216-223, 1987.

3) Okada O, Tanabe N, Yasuda J, et al. Prediction of life expectancy in patients with primary pulmonary hypertension. A retrospective nationwide survey from 1980-1990. Intern Med 38: 12-16, 1999.

4) Rich S, McLaughlin VV. The effects of chronic prostacyclin therapy on cardiac output and symptoms in primary pulmonary hypertension. J Am Coll Cardiol 34: 1184-1187, 1999.

5) Hinderliter AL, Willis PW, Barst RJ, et al. Effects of long-term infusion of prostacyclin (Epoprostenol) on echocardiographic measures of right ventricular structure and function in primary pulmonary hypertension. Circulation 95: 1479-1486, 1997.

6) McLaughlin VV, Genthner DE, Panella MM, Rich S. Reduction in pulmonary vascular resistance with long-term epoprostenol (prostacyclin) therapy in primary pulmonary hypertension. N Engl J Med 338: 273277, 1998.

7) Rubin LJ. Primary pulmonary hypertension. N Engl J Med 336: 111117, 1997.

8) Date $\mathrm{H}$. Current status and future of lung transplantation. Intern Med 40: 87-95, 2001.

9) Jones DK, Higenbottam TW, Wallwork J. Treatment of primary pulmo- nary hypertension with intravenous epoprostenol (prostacyclin). Br Heart J 57: 270-278, 1987.

10) Barst RJ, Maislin G, Fishman AP. Vasodilator therapy for primary pulmonary hypertension in children. Circulation 99: 1197-1208, 1999.

11) Takahashi T, Sakuma M, Nawata J, et al. A case with severe right heart failure due to primary pulmonary hypertension treated by epoprostenol and cardiotonic agent. Ther Res 21: 2032-2034, 2000.

12) Wharton J, Davie N, Upton PD, Yacoub MH, Polak JM, Morrell NW. Prostacyclin analogues differentially inhibit growth of distal and proximal human pulmonary artery smooth muscle cells. Circulation 102: 31303136, 2000.

13) Nagaya $N$, Nishikimi $T$, Uematsu $M$, et al. Plasma brain natriuretic peptide as a prognostic indicator in patients with primary pulmonary hypertension. Circulation 102: 865-870, 2000.

14) Nagaya N, Nishikimi T, Okano $Y$, et al. Plasma brain natriuretic peptide levels increase in proportion to the extent of right ventricular dysfunction in pulmonary hypertension. J Am Coll Cardiol 31: 202-208, 1998.

15) Miyamoto $S$, Nagaya $N$, Satoh $T$, et al. Clinical correlates and prognostic significance of six-minute walk test in patients with primary pulmonary hypertension: comparison with cardiopulmonary exercise testing. Am J Respir Crit Care Med 161: 487-492, 2000.

16) Rubin LJ, Groves BM, Reeves JT, Frosolno M, Handel F, Cato AE. Prostacyclin-induced acute pulmonary vasodilation in primary pulmonary hypertension. Circulation 66: 334-338, 1982.

17) Rubin LJ, Mendoza J, Hood M, et al. Treatment of primary pulmonary hypertension with continuous intravenous prostacyclin (epoprostenol): results of randomized trial. Ann Intern Med 112: 485-491, 1990. 